\title{
A 30 años de la ley de caducidad uruguaya ¿qué y cómo debemos conmemorar?
}

\author{
After 30 years of the Uruguayan expiry law, what and how should we \\ celebrate?
}

30 anos após a lei uruguaia de caducidade, o que é que devemos comemorar e como?

\author{
Ana Buriano \\ Silvia Dutrénit ${ }^{2}$
}

\section{RESUMEN}

A tres décadas de aprobación de la Ley 15 848, que impidió la aplicación de la justicia, el artículo se propone revisitar el tema a partir de un presente conmemorativo marcado por la distancia de una generación cronológicamente diferente en la concepción clásica orteguiana. Para ello delimitamos dos asuntos que consideramos centrales: el oscilante discurso político de los gestores de la ley y una batalla discursiva y memorística errática librada por la izquierda que, además, se encuentra atravesada por su arribo al gobierno. Treinta años después, cuando emerge una nueva generación se afirma una "cultura de la impunidad" ya no como un remanente transitorio sino un componente orgánico del sustrato cultural del hoy. En sus manos estará la asunción, reapropiación y reelaboración de ese pasado que no se logró depurar. Estas variables confluyeron en consolidar el silencio de los perpetradores y afirmar su espíritu de cuerpo.

Palavras-chave: Justicia transicional. Ley de Caducidad. Uruguay. Memoria. Impunidad.

ABSTRACT

Three decades after the passage of Law 15 848, which prevented the application of justice, the present article proposes to revisit the issue from a commemorative present marked by the distance from a

$1 \mathrm{El}$ texto es resultado parcial de la investigación que se realizapara el proyecto regional: "El trabajo de los equipos de antropología forense en América Latina: otra ruta de acceso al conocimiento de la represión y violencia políticas". CONACYT-Mora, clave CB 2012/177295.

2 Instituto Mora - MX. 
chronologically different generation in its classical Ortegan conception. To do this, we delimited two issues that we considered fundamental: the oscillating political discourse of the lawmakers, and an erratic rote discursive battle fought by the left, which in addition coincided with its arrival to power. Thirty years later, when a new generation emerged a "culture of impunity" consolidated no longer as a transient remnant, but as an organic component of today's cultural background. It was in charge of taking over, reapprop riating and reworking the past for depuration. These variables came together to consolidate the silence of perpetrators and affirm their esprit de corps.

Keyword: Transitional justice. Law Nullifying the State's Claim to Punish Certain Crimes. Uruguay. Memory. Impunity.

\section{RESUMO}

Três décadas após a aprovação da Lei 15.848, o que impediu a aplicação da justiça; este artigo se propõe rever a questão a partir de um presente comemorativo, marcado pela distância de uma geração cronológica diferente na concepção clássica "Orteguiana". Para isso delimitamos duas questões que consideramos centrais: o discurso político oscilante dos gestores da lei e, uma batalha discursiva e memorista errática conduzida pela esquerda, que para além de tudo, também é atravessada por sua chegada ao governo. Trinta anos mais tarde, quando uma nova geração surge, uma "cultura de impunidade" está consolidada, não como um remanescente de transição, mas, outro sim, como um componente orgânico do fundo cultural de hoje. Nas suas mãos fica a retomada, reapropriação e releitura do passado que não se conseguiu depurar. Essas variáveis convergiram para consolidar o silêncio dos responsáveis e afirmam o seu "esprit de corps".

Keyword: Justiça de Transição. Anistia Lei. Uruguai. Memória. impunidade.

"Dicen que no hay que remover el pasado, que no hay que tener ojos en la nuca, que hay que mirar hacia adelante y no encarnizarse en reabrir viejas heridas. Están perfectamente equivocados. Las heridas aún no están cerradas.

Laten en el subsuelo de la sociedad como un cáncer sin sosiego. Su único tratamiento es la verdad. Y luego, la justicia. Sólo así es posible el olvido verdadero". En primera fila le escuchaba atentamente Macarena. Los dos siguen buscando los restos de María Claudia, por poder tener un lugar, como ha reclamado Juan Gelman, donde al menos depositar para ella un ramo de flores.

Palabras de Juan Gelman al recibir el Premio Cervantes en Alcalá de Henares, el 23 de abril de 2008. (CAÑAS, 2008). ${ }^{3}$

La justicia -afirma Ricoeur- (2004, p. 119-120) "extrae de los recuerdos traumatizantes su valor ejemplar, transforma la memoria en proyecto; y es este mismo proyecto de justicia el que da al deber de memoria la forma del futuro y del imperativo". La justicia es ese tercer

3 Juan Gelman falleció el 14 de enero de 2014 en México sin haber logrado encontrar los restos de María Claudia. 
término que media entre el trabajo del duelo y el trabajo de la memoria que avanza hasta alcanzar la dimensión de la verdad. Este tercer término es el que obturó la Ley de Caducidad de la Pretensión Punitiva del Estado en Uruguay, a año y medio de restablecida la institucionalidad posdictatorial con consecuencias profundas para la reconstitución del tejido social uruguayo.

Sin embargo las catástrofes, de cualquiera origen -natural o social- (JELIN, 2002, p. 11), ${ }^{4}$ son incapaces de interrumpir el curso de los tiempos en función de la capacidad reconstitutiva de la humanidad. Cierto es que las sociedades no regresan indemnes desde ellas. Es habitual decir que los pasados traumáticos están en el presente con resquicios, desechos, sobras constatables. De la tramitación que las sociedades logren dar a esos pasados dependerá su capacidad de liberarse de ellas o la necesidad de absorberlas como partes constitutivas de su ser social colectivo.

Una vez que los Estados se reinstitucionalizaron, se vieron exigidos por demandas sociales que los impulsaban a asumir el reto de ese pasado de horror. Mayoritariamente, y muy especialmente el Estado uruguayo y los sucesivos gobiernos transicionales $\mathrm{y}$ postransicionales, no percibieron estas demandas como un instrumento restaurador de los tejidos sociales. Por el contrario, tendieron a visualizarlas como distorsionadoras del proceso de redemocratización. Especialmente en aquellos países donde la salida de las dictaduras estuvo signada por pactos, la justicia transicional (RINCÓN, 2010; TEITEL, 2011; DE GREIFF, 2011) enfrentó muchos obstáculos. Más allá de las múltiples visiones, el concepto de justicia transicional alude a la justicia que se aplica en respuesta a graves violaciones cometidas por los Estados y que comprende acciones judiciales retributivas y medidas políticas restaurativas, una vez restablecido un marco jurídico institucional mínimamente aceptable. Lógicamente, como señala De Greiff (2011), la aplicación de esta justicia no está sujeta a una temporalidad específica inmediata tanto por el carácter de los delitos cuanto por los deficientes desempeños de los poderes estatales. Algunos especialistas trabajan sobre el concepto de justicia postransicional vinculado a los subsiguientes gobiernos con la idea de poderes judiciales relativamente mas independientes en el cumplimiento de ciertos requisitos del proceso de reinstitucionalización de los Estados. (COLLINS, 2010; SKAAR, 2012).

En este artículo deseamos retomar algunos problemas que han merecido reflexión ante la persistencia de la Caducidad y su incidencia en la configuración del presente. Delimitaremos dos asuntos que consideramos centrales a la hora conmemorativa: el oscilante discurso político de los gestores de la ley y una batalla discursiva y memorística errática librada por la izquierda atravesada, además, por su arribo al gobierno. Ambos confluyeron en consolidar el silencio de los perpetradores.

4 Jelin (2002) toma la noción de "catástrofe social" de Kaës (1991) quien asume la propuesta de Freud en el sentido de diferenciar los efectos de ambas sobre el cuerpo social: mientras las catástrofes naturales lo solidarizan, las sociales desagregan y dividen. 
30 años atrás, en diciembre de 1986, y luego de una serie de amenazas de desacato a los citatorios del poder judicial se instaló un modo de amedrentamiento a sectores de la clase política y la sociedad de carácter teatral. (DE GIORGI, 2013, p. 30). Los implicados en crímenes de lesa humanidad se negaban a presentarse ante el juzgado con apoyo de sus mandos, en desacato total al poder civil. Julio María Sanguinetti, el primer presidente del periodo posdictatorial (1985-1990), obtuvo las mayorías parlamentarias para lograr la aprobación de una ley de amnistía denominada Ley de Caducidad de la Pretensión Punitiva del Estado (Ley 15 848). ${ }^{5}$ Ella hacía caducar la obligación estatal de juzgar al personal militar, policial y equiparado que hubiera cometido delitos de lesa humanidad durante el periodo de facto. Su artículo 4to. posibilitaba investigar y judicializar algunas violaciones en ciertos casos, como niños secuestrados, legisladores asesinados y personas desaparecidas fuera de las fronteras. Era, por supuesto, inconstitucional pues, violaba la separación de poderes ya que sometía el Poder Judicial a la decisión del Ejecutivo a fin de que éste le autorizara tramitar las denuncias o las amparara en la ley. ${ }^{6} \mathrm{~A}$ la vez, parecería contraria a un bien internalizado sentido común nacional de igualdad, pues admitía la existencia de estatutos diferenciales entre los perpetradores de delitos. Más allá de la galimatía semántica era finalmente una amnistía.

Durante tres décadas y desde sectores de la sociedad civil vinculados a los emprendimientos en favor de los derechos humanos (DDHH) se impulsaron mecanismos para anularla primero y derogarla luego, por medio de un referéndum en 1989 y un plebiscito en 2009. Existió también una tardía reacción desde el propio Parlamento en 2011 por restablecer la punitividad del Estado (URUGUAY, 2011) y conjurar los dañinos efectos de la prescripción de los crímenes. Tampoco ella prosperó pues la Suprema Corte de Justicia (SCJ) uruguaya declaró inconstitucionales los artículos 2do y 3ro que establecían la condición de delitos de lesa humanidad para los crímenes ocurridos durante el periodo de facto y ordenaba no computar plazo procesal de prescripción entre la aprobación de la Ley

\footnotetext{
5 Uruguay. Ley 15. 848. 1986. Funcionarios militares y policiales. ... Capítulo 1. Artículo 1ero. Reconócese que [...] ha caducado el ejercicio de la pretensión punitiva del Estado respecto de los delitos cometidos hasta el lero. de marzo de 1985 por funcionarios militares y policiales, equiparados y asimilados... que actuaron durante el periodo de facto. Artículo 2do. Lo dispuesto... no comprende [...] Los delitos que se hubieren cometido con el propósito de lograr... un provecho económico. Artículo 3ero. [...] el juez... requerirá al Poder Ejecutivo que informe... si el hecho investigado lo considera comprendido o no en el Artículo 1ero. de la presente ley. Si el Poder Ejecutivo así lo comunicare, el juez dispondrá la clausura y el archivo de los antecedentes [...] Artículo 4to. Sin perjuicio de lo dispuesto ... el juez de la causa remitirá al Poder Ejecutivo testimonios de las denuncias presentadas hasta la fecha de promulgación de la presente ley referentes a actuaciones relativas a personas presuntamente detenidas en operaciones militares o policiales y desaparecidas así como de menores presuntamente secuestrados en similares condiciones. El Poder Ejecutivo dispondrá de inmediato las investigaciones destinadas al esclarecimiento de estos hechos." Un texto del Centro Uruguay Independiente resulta una fuente sustantiva que reúne principales documentos que ilustran el contexto que conduce a la aprobación de la ley, su inconstitucionalidad, el camino al referendum y las voces de actores destacados de la realidad nacional. (URUGUAY, 1986).

6 En 1986, la Suprema Corte de Justicia (SCJ) declaró la imposible constitucionalidad dela Ley de Caducidad por mayoría, con dos votos en contra. Bajo una nueva integración, en octubre de 2009, este mismo órgano estableció su inconstitucionalidad para varios casos. Ello no significó el fin de la Caducidad pues la SCJ sólo actúa sobre casos específicos y carece de competencia genérica para establecer la constitucionalidad de las leyes.
} 
de Caducidad en diciembre de 1986 y su entrada en vigencia. ${ }^{7}$ En los últimos años y con la llegada al poder del Frente Amplio (FA) se impulsaron estrategias que permitieron lo que se llamó "perforaciones" a la Ley. Resultado de ellas fue el procesamiento de algo más de una decena de perpetradores, incluidos dos civiles -el presidente golpista- Juan María Bordaberry, y el canciller de la dictadura, Juan Carlos Blanco.

Con el tiempo transcurrido, una generación cronológica que ha vivido bajo la vigencia de la Caducidad y ante la conmemoración de una fecha lamentable para la defensa y promoción de los DDHH, emergen nuevas preguntas y balances revestidos por la madurez del acontecer. En los últimos años algunos académicos han retomado el tema desde distintas y nuevas perspectivas que no agotaremos en esta enumeración: la mecánica utilizada para deshacerse de la Ley, los discursos elaborados en torno a la misma, la responsabilidad social y de los sectores políticos a partir de sus resultados, las visiones jurídicas y la Ley como columna vertebral articuladora de luchas por la memoria. ${ }^{8}$ Estas consideraciones tienen un punto de partida común en todos los autores: el reconocimiento de la instalación a nivel nacional de lo que se dio en llamar una "cultura de la impunidad". Tal afirmación, que responde a una realidad de impunidad sostenida, no puede asimilarse de forma monolítica y dejar de lado la pluralidad de las culturas. En el caso uruguayo esta pluralidad ha tenido instancias que han hecho posible su medición; la última de ellas, el plebiscito de 2009, mostró un país hondamente dividido en cuanto al tema: un $52 \%$ abrevó la impunidad, un $48 \%$ la reprobó.

Hay que recordar que el renacer de la democracia vino acompañado de un discurso que se tornó hegemónico desde el poder, el de la impunidad, que abusa de una tradición que emerge desde el fondo de una historia, no muy lejana como la uruguaya, en que se reivindica el fin de la Guerra Grande (1852) con el lema de "ni vencidos ni vencedores" y que al mismo tiempo amenaza, luego de una experiencia dictatorial de más de una década, sobre la posible rebelión de las Fuerzas Armadas (FFAA) ante la acción de la justicia civil. Con los cambios por y en la gestión gubernamental ese discurso hegemónico raigal del Uruguay transicional (sostenido por la inmensa mayoría de los partidos tradicionales Colorado y Blanco) articuló una narrativa. Años más tarde y con sus matices, ese relato se retroalimentó y reformuló con el de algunos sectores, especialmente líderes de los otrora víctimas de la dictadura.

7 Uruguay. Ley $\mathrm{N}^{\mathrm{o}}$ 18.831. (URUGUAY, 2011). Pretensión punitiva del Estado...Artículo $1^{\circ}$.- Se restablece el pleno ejercicio de la pretensión punitiva del Estado para los delitos cometidos en aplicación del terrorismo de Estado hasta el $1^{\circ}$ de marzo de 1985 ... Artículo $2^{\circ}$.- No se computará plazo alguno, procesal, de prescripción o de caducidad, en el período comprendido entre el 22 de diciembre de 1986 y la vigencia de esta ley, para los delitos a que refiere el ar tículo $1^{\circ}$ de esta ley. Artículo $3^{\circ}$.- Declárase que, los delitos a que refieren los artículos anteriores, son crímenes de lesa humanidad de conformidad con los tratados internacionales de los que la República es parte.

8 Entre los académicos que han abordado, con distintos cortes analíticos la ley, deben mencionarse los trabajos de Allier, E.; Bardazano, G.; Buriano, A.; Caetano, G.; Demasi, C.; Dutrénit, S. y Varela, G.; Fried, G.; De Giorgi, A.; De Giorgi, A. L.; Lessa, F.; Marchesi, A. Rico, A, y Sempol, D. 


\section{Los artífices de la ley y su discurso.}

Cuando nos aproximamos a considerar el discurso hegemónico no podemos desconocer el liderazgo e incidencia de los partidos políticos sobre la sociedad y su papel como formadores de opinión que ejercieron desde su origen y muy particularmente durante la transición a la democracia. Sin intentar siquiera un estudio de los partidos uruguayos en y pos la transición creemos necesario señalar que, históricamente, la sociedad civil y partidos han tenido una intensa compenetración hasta el punto que Varela (1981, p. 59) la describe como "un magma indefinido" que se derrama sobre la sociedad uruguaya e impregna sus intersticios. Si bien es cierto que ese sistema político se vio aminorado en el periodo inmediatamente predictatorial, retornó fortalecido, bajo los nuevos aires institucionales.

El discurso de la clase política tradicional mantuvo algunas constantes pero no fue de ninguna manera monolítico ni ahistórico. Tuvo una gran capacidad de penetración y de construcción discursiva. No puede despreciarse la ventaja incuestionable que les dio el monopolio del poder estatal que ejercieron durante veinte años, entre marzo de $1985 \mathrm{y}$ marzo de 2005 compartida entre ambos partidos, el Colorado y el Blanco. Tampoco desconocer que su intención fue disculpar y disimular las no pocas responsabilidades que adquirieron con su actuación inmediatamente anterior al golpe de Estado, tanto por la pérdida de representatividad y capacidad de mediación de sus partidos, como por su activo desmontaje de la institucionalidad, ${ }^{9}$ para desplazarlas en sentido inverso, hacia el movimiento armado ya aniquilado cuando se consumó el golpe de Estado. (BURIANO, 2013).

Aprobada la Ley, los discursos de los legisladores blancos y colorados se bifurcaron. Paradójicamente quien fue un férreo enemigo de la dictadura -que trató sin éxito de eliminarlo en el marco de la Operación Cóndor en Buenos Aires- tuvo una acción determinante en su elaboración. Wilson Ferreira Aldunate, legislador blanco y figura destacada de la oposición en el exilio fincó, en 1986, la explicación de su apoyo en el carácter indigno de la salida pactada, en la que se negó a participar y que siempre repudió en tanto lo proscribió como candidato para las primeras elecciones posdictatoriales. ${ }^{10}$ Sellada la suerte

9 La referencia es a la declaratoria de Estado de Guerra Interno y a la Ley de Seguridad Nacional ambas aprobadas por sendas cámaras del Parlamento reunidas en Asamblea General en 1972 con el voto casi unánime de la clase política tradicional. Tanto la Declaración como la Ley constituyen un escalón significativo en la reestructura autoritaria del Estado aun antes de consumado el golpe de Estado. Luego de construir la figura de un enemigo, el subversivo, los dos instrumentos establecían, entre otras medidas represivas, la competencia de la justicia militar para juzgar casos los civiles así configurados, además de crear una serie de figuras delictivas generalmente caracterizadas como "atentados" (a la Constitución, al honor de las fuerzas armadas, asistencia a la subversión, etc.) Para un tratamiento específico Véanse Rico (2005); Rey Tristán (2005).

10 La referencia es al Acuerdo del Club Naval entre militares y civiles. Éstos representaban a los partidos políticos con la ausencia ex profeso del Partido Nacional o Blanco. El Acuerdo también conocido como Pacto ha sido analizado y ha generado polémica desde su momento inaugural hasta el presente. Dos interesantes textos, escritos tempranamente, contienen entrevistas a distintos protagonistas de ese momento emblemático. Nos referimos al de Achard(1992); y al de Gillespie (1991). 
del Uruguay en ese pacto, la impunidad quedó incrustada en aquel acto ilegítimo y por tanto era su hija más prístina que debía ser reconocida para que, al salvar la institucionalidad, el sistema político se saneara a sí mismo. (DE GIORGI, 2013) Es probable que lo sostenido por Ferreira Aldunate no fuera ajeno a cierta compensación personal, particularmente contra la principal víctima del proceso dictatorial, la militancia y dirigencia del FA participante del Pacto del Club Naval que lo dejó fuera del juego político. Sin embargo, su iniciativa no fue acompañada por todos sus correligionarios. Carlos Julio Pereyra, líder del Movimiento de Rocha aliado del wilsonismo, formó parte de los pocos sectores de los partidos tradicionales que no votaron la Ley en el Parlamento. ${ }^{11}$

Es de valorar que con el transcurrir del tiempo, el hijo del líder blanco y también acompañante de la iniciativa, Juan Raúl Ferreira, haya solicitado reiteradas disculpas y exaltado el carácter no decididamente amnistiante de su formulación a partir del ejercicio del artículo 4to. Desde este presente, el destacado militante por los derechos humanos, quien ha presidido la Institución Nacional de Derechos Humanos (INDH) interpreta el sentir del líder entonces y el suyo propio, al decir:

\begin{abstract}
Votamos con dolor..., Wilson temía [que] los militares lisa y llanamente desacataran las citaciones judiciales. ...Eso me permite sentir orgullo al pedirle a todos ustedes perdón por haber votado esa ley que aún ha dejado puñados de cultura de impunidad en sectores de la población. (FERREIRA, 2016).
\end{abstract}

En 1988 falleció Ferreira Aldunate y su partido, bajo la conducción de Luis Alberto Lacalle perseveró, junto con el Partido Colorado, por mantener la Ley e imponer la narrativa dominante. Esa narrativa alimentada por ambos partidos no debe invisibilizar, pese a sus vaivenes, que el gran elaborador de su matizado y penetrante contenido fue el Partido Colorado. Es más, el verdadero artífice, tanto de la solución pactada en el Club Naval cuanto de la Ley de Caducidad, fue el dos veces presidente Julio María Sanguinetti, quien también fue ministro de Juan María Bordaberry. Sanguinetti, apostó inicialmente a lo que se ha dado en llamar "simetría de la culpa" fundamento de la "simetría de la solución". ${ }^{12}$ Los

11 Véanse el pronunciamiento y distintos documentos sobre la postura en aquella coyuntura del Movimiento Nacional de Rocha que lideraba Carlos Julio Pereyra en (CENTRO URUGUAY INDEPENDIENTE, 1987).

12 "Otro fundamento del no juzgamiento es el de la simetría de la culpa, tal como fue expuesto, entre otros, por el ex presidente uruguayo José María Sanguinetti (WESCHLER,1990) suponiendo que si hubo amnistía amplia para los presos de izquierda también debería haberla para los militares. Es un pretexto invocado con cierta frecuencia, pero aparte de que el sufrimiento infligido por militares y fuerzas represivas en general no tuvo proporción con el que causaron sus víctimas, éstas, en su gran mayoría, no tuvieron un debido proceso ni su culpabilidad fue probada en juicios con garantías, por lo que ambas situaciones son incomparables. Como ya se dijo, por ejemplo en Argentina un número inconmensurable de afectados presumiblemente no militaba en organizaciones militares clandestinas o no había participado en la planeación, ejecución o encubrimiento de acciones guerrilleras (STRASSERA; MORENO OCAMPO, 1986). 
responsables debían ser tan amnistiados, como lo habían sido los integrantes del Movimiento de Liberación Nacional-Tupamaros (MLN-T) que cometieron delitos de sangre. Es decir, en su lógica interpretativa amnistiados los presos políticos, por la vía de la Ley 15 737 de Pacificación, correspondía exonerar a sus verdugos. (BURIANO, 2011, p. 176). Esta valoración refería a quienes habían tomado el camino de las armas y le fue útil para asentar en ella su falsa teoría de los dos demonios. No obstante omitía que mientras los hombres de las FFAA no habían pasado un solo día por la prisión, los integrantes del MLN-T habían sido sometidos a torturas sistemáticas, encarcelados bajo condiciones extremas de castigo por más de una década y se les había efectuado un juicio que, aunque viciado en su raíz por las condiciones de tortura que privaron bajo la justicia militar, establecía una equiparación de tres años de prisión en las cárceles de la dictadura por uno de pena. (CENTRO URUGUAY INDEPENDIENTE, 1987).

Con la ventaja de mirar aquella estrategia discursiva a tres décadas de aprobada la ley, es factible afirmar que se trató de una construcción elaborada ex profeso para hegemonizar la memoria social, aplastar la de las víctimas y consagrar la impunidad. No se debe olvidar que Sanguinetti es un político diestro y conocedor de la idiosincracia uruguaya. Hiló finamente la urdimbre para aplicar con éxito la teoría de los dos demonios que establecía candados para evitar una vuelta atrás de la Ley. (DEMASI, 2003). Es decir, elaboró una idea rectora sobre la sociedad uruguaya que la posicionaba como aquella inocente que fue aprisionada en los años setenta por dos fuerzas enfrentadas. Dos bandos enloquecidos habían dado vida a una dictadura, exógena al sentir nacional, interrumpido la tradicional convivencia pacífica e inaugurado una etapa histórica que por ajena merecía ser olvidada. (MARCHESI, 2013). Era necesario evitar un escenario similar en la posdictadura y las exigencias de justicia sólo conducirían a un nuevo enfrentamiento entre el temor natural a un "ajuste de cuentas" de un sector acostumbrado por razones profesionales a atacar y la impaciencia de otros que, con una mentalidad intelectualizada, aspiraban a la plenitud del restablecimiento del Estado de derecho. (SANGUINETTI, 1991). Este discurso omitía, sin ética, la extendida represión contra luchadores sociales que mayoritariamente sólo esgrimieron el arma de sus reivindicaciones políticas y sociales.

Así se fue erigiendo, desde el campo de los impulsores y defensores de la ley, un ambiente de reconciliación desprovisto de verdad y justicia. Con éxito zigzagueante fueron ganando terreno "los deberes del olvido" para la paz y reconciliación sanguinettiana. Convencidos unos que la justicia transicional y la verdad socavaban la gobernabilidad de la renacida democracia, cómplices otros de los autoritarismos impuestos por los gobiernos

Para los represores sólo se ha pedido un juicio justo que termine con la situación de impuni dad, mientras los otros, en gran número, sufrieron un castigo brutal e indebido, siendo muchos jurídicamente inocentes al no haber sido sometidos a un debido proceso. De acuerdo con esta lógica, en Uruguay la Ley de Pacificación de 1985 que permitió la lib eración de los presos políticos, reconoció la desproporcionalidad del castigo (e implícitamente, la irregularidad de los juicios correspondientes) al liberar anticipadamente a los acusados de delitos de sangre por motivos políticos (Ley de Pacificación Nacional 15.737)”. (DUTRÉNIT; VARELA, 2010, p. 99). 
cívico-militares, nada mejor entonces que refundar la nación desde la impunidad, como las renanianas "comunidades del olvido". (BURIANO, 2012). ${ }^{13}$

\section{Los opositores a la ley: la izquierda partidaria y los emprendedores}

El sentimiento de repudio a la aprobación de la Ley de Caducidad, el 22 de diciembre de 1986 fue unánime entre las organizaciones sociales, el movimiento sindical, los sectores políticos que conformaban el FA e incluso el MLN-T que todavía no formaba parte de la coalición frenteamplista. Ello derivó en lo inmediato en la formación la Comisión Na cional Pro Referéndum. Madres y Familiares de Detenidos Desaparecidos lanzó la iniciativa de utilizar el mecanismo previsto en la Constitución. ${ }^{14}$ En febrero de 1987 la Comisión quedó instalada y presidida por esposas y abuela emblemáticas de víctimas de la dictadura, Elisa Dellepiane de Michelini, Matilde Rodríguez de Gutiérrez Ruiz y María Esther Gatti de Islas. Tuvo una integración que representaba a distintos ámbitos de la sociedad uruguaya: la cultura, la educación, el sindicalismo, el deporte y la política. El FA adhirió a la iniciativa y también acompañaron sectores de los partidos tradicionales, quienes se habían opuesto a la aprobación de la Ley en el Parlamento. (BUCHELI, 2005, p. 64). Si bien la convocatoria se presentó como ciudadana, en un gran esfuerzo por ampliar el espectro político y no restringirlo a la izquierda, fueron las estructuras partidarias las únicas capaces de solventar en enorme desafío que significó reunir las firmas de la cuarta parte del electorado para someterla a referéndum.

Los resultados negativos arrojados el 16 de abril de 1989, día en que se llevó a cabo el referendum -primera de las dos instancias de consulta ciudadana en un arco temporal de 20 años- confirman el espectro estrictamente partidario que no todos los analistas reconocen. ${ }^{15}$

13 La expresión “comunidades del olvido" se retoma de Georges Lomné quien la utiliza en referenciaa la propuesta de E. Renán, en su Conferencia de 1882 en la Sorbonne cuando proclamó como esencia de una nación la preservación de un legado común de recuerdos, acompañados por muchos olvidos (BURIANO, 2012, p. 475-476).

14 La Constitución uruguaya prevé dos instancias de consulta ciudadana directa: los plebiscitos (Art. 331) que exigen el apoyo del $10 \%$ del electorado y que se utilizan para reformar la Constitución y algunas iniciativas de ley y los referéndums. Esta última figura apareció por primera vez en la historia constitucional del país con el artículo 79 de la Constitución de 1967 que establecía el derecho ciudadano de anular una ley durante el primer año de su aprobación, en tanto la iniciativa fuera acompañada por la firma del $25 \%$ del electorado.

15 El 41.3\% de aprobación que logró la iniciativa opositora a la ley, en abril de 1989, refleja exactamente la votación que obtuvieron los sectores políticos involucrados en la campaña siete meses después. Un análisis realizado por Puchet, registra que los casi 800 mil votos que obtuvo la papeleta verde por la derogación, se conformaron con los 600 mil votos que obtuvieron el FA, Nuevo Espacio, así como gran parte de los votantes de un sector del Partido Nacional opuesto a la Ley, además de alguna fracción colorada de esa misma tesitura en las elecciones nacionales de noviembre de ese mismo año. Lo mismo puede constatarse en el voto favorable a su mantenimiento confrontado con la elección correspondiente. (PUCHET, 1990, p. 220). 
De modo que las fidelidades partidarias se sobrepusieron entonces al compromiso cívico ciudadano.

La negativa a anular la ley fue crucial para su asentamiento, para la narrativa en torno a la misma y para la construcción memorística hegemónica. Debe considerarse que la apelación al mecanismo del referéndum devenía de dos factores: era el único instrumento constitucionalmente habilitado para deshacerse de una ley que maculaba la democracia uruguaya. Pero además respondía a una lectura algo simplista donde la categoría pueblo era entendida de forma monolítica y cuyo espíritu democrático, solidario y bondadoso estaba fuera de cuestión. Era una visión romantizada al decir de Aldo Marchesi (2013) del ser nacional a despecho de su comportamiento en el plebiscito de 1980 convocado por la dictadura para institucionalizarse, que si bien fue derrotado contó con un $42 \%$ de apoyo al cronograma dictatorial. ${ }^{16}$

Más allá de las interpretaciones que se dieron y pudieran darse a este primer intento cierto es que tuvo consecuencias de largo aliento para la sobrevida de la Ley. Sus artífices vieron en esta derrota la confirmación del acierto de su solución. Sanguinetti decretó que este resultado confirmaba el éxito de la transición uruguaya que dio por terminada en ese instante. Sostuvo entonces que el tema estaba definitivamente laudado y revestido de la legitimidad incuestionable que le otorgaba el refrendo de la soberanía popular. Vox populi vox dei, no en su sentido providencial ajeno a la sociedad uruguaya era, sin embargo, un valor largamente reivindicado particularmente por la izquierda que veía en las instancias de democracia directa un mecanismo de control popular a la clase política tradicional. El referéndum era constitucionalmente posible pero restó responsabilidad y cobijó a esa clase política autora de la Ley, al tiempo que diseminó la culpa en el conjunto social.

Este resultado tuvo, y de manera determinante, un impacto sobre la izquierda partidaria, parte de la cual lo asumió como una realidad indeseable pero inamovible. Esta izquierda resultaba una recién llegada, como problematiza Markarian, al movimiento de derechos humanos y apenas salida del discurso antisistémico sesentista. ${ }^{17}$ Sobre ella pesaban más las determinantes nacionales y vivían las conmociones del entorno internacional. El más próximo, el regional era también poco propicio dadas las leyes de Punto final y Obediencia debida en Argentina, ${ }^{18}$ Chile apenas emergía de la dictadura

16 En noviembre de 1980 se sometió a plebiscito una reforma constitucional sin ninguna participación de los partidos que pretendía con el vo to de la ciudadanía institucionalizar un régimen tutelado de acuerdo a la estrategia dictatorial. La ciudadanía se inclinó por el No a la reforma por más del $57 \%$ de los votos.

17 Vania Markarian se pregunta: "Por qué muchos militantes adoptaron un discurso político largamente asociado al anticomunismo de la Guerra Fría?" Y se responde en un primer momento que "los exiliados uruguayos empezaron a usar el lenguaje de los derechos humanos al reconocer que su espacio de militancia revolucionaria en el Cono Sur se estaba reduciendo dramáticamente. Este reconocimiento fue lento..." Esta mirada analítica con mayor profundidad la trabaja en su artículo (MARKARIAN, 2004, p. 85-108).

18 Dos leyes que absolvieron a los integrantes de la estructura militar con el argumento de que ya se había enjuiciado a los “verdaderos responsables". En la Ley 23.521 de Obediencia Debida, decretada en 1987, se dice que las fuerzas armadas "no son punibles por los delitos" de violación a los derechos humanos, por haber obrado "en estado de coerción bajo la subordinación a la autoridad superior y en cumplimiento deórdenes" y en la Ley 23.492 de Punto Final promulgada en 
pinochetista y Brasil con su autoamnistía no resultaba un referente en materia de tratamiento del pasado violatorio de derechos humanos. La izquierda uruguaya resentía los efectos de estos trastornos, sin embargo crecía electoralmente, al punto de ganar la intendencia de Montevideo en 1989. Ello seguramente influyó en el intenso viraje interpretativo que sufrió. A medida que se aproximaba a su objetivo máximo, las luces del futuro la encandilaban con más fuerza que las oscuridades pretéritas.

En esas condiciones la gestión social del pasado se vio extraordinariamente trabada. No es exagerado hablar de un estado de pasmo social de más de un lustro, cargado de silencios. Nada prosperó en los largos años que pusieron fin al siglo XX. Ningún juicio fue considerado, ni siquiera los que involucraban a menores apropiados. Por el contrario, desde sus presidencias (1985-1990 y 1995-2000), Sanguinetti obstruyó la posible recuperación de la identidad por lo menos de dos menores y Lacalle (1990-1995) toleró el accionar de Cóndor en el país. ${ }^{19}$

Vedada toda posibilidad de justicia, la memoria resistente de Familiares y emprendedores se refugió en el territorio de la verdad. Junto con los cambios en la sensibilidad internacional, las conmemoraciones también actuaron sobre el Uruguay de la impunidad total. En 1996 y en recuerdo del emblemático asesinato de dos legisladores uruguayos, de dos ex integrantes de la guerrilla urbana y la desaparición de un militante comunista en Argentina en el marco del operativo de coordinación regional, Madres y Familiares instituyeron su Primera Marcha del Silencio. El lema fundacional es muy significativo -Por verdad, memoria y nunca más-, y las siguientes consignas lo son respecto de la evolución que ha tenido en el país ese tratamiento del pasado. ${ }^{20}$ Sólo verdad, sólo memoria y además un muy demostrativo y elocuente "silencio". ${ }^{21}$ Así fue ganando espacio entre ciertos sectores de la izquierda la sensación de que el tema podía ser objeto de trueque. De que los derechos podían ser intercambiables una vez rota su unicidad. Verdad y memoria en lugar de justicia, siempre y cuando ella se reclamara en el silencio social que había impuesto la voluntad soberana el 16 de abril de 1989.

Fue en este marco de aminoramiento de las aspiraciones que el gobierno colorado de Jorge Batlle (2000-2005) abrió por primera vez un resquicio de reconocimiento a la problemática. Se reunió con Madres y Familiares y convocó, al inicio de su gestión, en 2000, a una Comisión denominada "para la Paz" (COMIPAZ) e integrada por principales figuras

1986 se extingue "la acción penal respecto a toda persona por su presunta participación en cualquier grado, en los delitos..." que violan los derechos humanos. (ARGENTINA, 1987; ARGENTINA, 1986).

19 Los niños secuestrados y con cambio de identidad que luego fueron recuperados son Simón Riquelo y Macarena Gelman. El suceso del accionar del Cóndor durante el gobierno de Lacalle refiere a la participación de oficiales uruguayos en el asesinato del químico chileno Eugenio Berríos en territorio nacional. Berríos fue miembro de la Dirección de Inteligencia Nacional elaborando armas químicas como gas sarín y otros químicos. Se le relacio na con la muerte del ex presidente chileno Eduardo Frei Montalva.

20 En el portal de Madres y Familiares de Detenidos Desaparecidos es posibleapreciar algunos de los lemas convocantes desde 1996 para las Marchas del Silencio de los 20 de mayo. Asimismo ofrece este portal una información amplia sobre el trabajo de familiares y los casos de detenidos desaparecidos. Disponible en: <http://desaparecidos.org.uy/page/25/>. 21 En el libro de Allier (2010, p.154-155) se hace mención a los lemas y sus significados apoyado en algunas fuentes orales. 
del mundo religioso, representantes de los partidos, de ONG'S y del sindicalismo con el cometido de recibir testimonios, analizarlos y clasificarlos y producir un informe. ${ }^{22}$ Fue una instancia que no tuvo formato ni pretensiones de comisión de la verdad, aun cuando cada una tiene su singularidad. ${ }^{23}$ Su nominación anticipa ese carácter distinto que, en sus marcos acotados, evidenció por sobre todo que había una deuda con el esclarecimiento de lo sucedido. COMIPAZ recabó algunos casos, recibió algunos testimonios falsos sobre el destino de los detenidos desaparecidos y produjo, tres años después, un Informe final. ${ }^{24}$ Más allá de las buenas intenciones de algunos integrantes y las no tan buenas de otros, cierto es que este documento no satisfizo a muchos y quedó fuertemente cuestionado a medida que otras instancias y descubrimientos fueron mostrando sus limitaciones. Ni que decir que en las épocas del silencio debe valorársele como una primera instancia de apertura, no obstante su nombre indicaba una vocación gubernamental de convocatoria que distorsionaba el fondo de lo acontecido y una decisión de cierre de la investigación: la pacificación del país y el carácter final de la verdad obtenida.

Irrefutable es que en el mismo 2000 y previo a la creación de la Comisión, se había logrado la recuperación, por investigaciones privadas y reconocimiento oficial, de una de las menores sustraídas que vivía en Uruguay como hija de un jefe policial y en los años inmediatos otro de una madre uruguaya sobreviviente cuya residencia estaba en Buenos Aires. $^{25}$

En tanto se procesaba ese pasado, adquiría cierta presencia en el espacio público y a en los medios, el FA se aproximaba al poder con preferencias político-electorales que parecían favorecerlo. Con una composición ligeramente modificada y un acercamiento al centro del espectro realizó su Congreso IV Congreso, el de la "Victoria" como se le llamó, donde debatió su programa de gobierno y dentro de él lo relativo al tratamiento del pasado reciente y la Ley de Caducidad. Hasta ese momento para el FA había sido su "causa sagrada" (DE GIORGI, 2013), no extraño a una comunidad política sobre la que recayó, al menos a algunos de sus integrantes, la mayor fuerza de la represión durante toda la dictadura, y único sector partidario que monolíticamente votó contra la Ley. En adelante, los años transcurridos luego del fracaso del primer emprendimiento con el halo inviolable de las consultas populares y diversos factores que no es posible analizar en este artículo, introdujeron

22 La Comisión para la Paz funcionó en el ámbito de la Presidencia de la República y tuvo una integración simbólicamente representativa de destacados sectores na cionales como son: Monseñor Nicolás Cotugno (Arzobispo de Montevideo); José D'Elía (dirigente histórico del sindicalismo, PIT-CNT); sacerdote Luis Pérez Aguirre (dirigente de SERPAJ y representante de los familiares); Dr. Claudio Williman (universitario del Partido Nacional); Dr. Gonzalo Fernández (representante de líder del Frente Amplio-Encuentro Progresista, Tabaré Vázquez) y el Dr. Carlos Ramela (asesor presidencial y delegado en la Comisión).

23 Véase sobre el tema de comisiones de la verdad los libros de Hayner (2001) y Espinoza Cuevas; Ortíz; Rojas Baena (2002).

24 Un análisis del informe final se encuentra en Dutrénit (2003).

25 Son los casos mencionados en la nota 18. Simón Riquelo y Macarena Gelman fueron entregados tal cual botín de guerra a familias de policías. Con anterioridad se habían recuperado algunos menores. 
modificaciones internas sensibles en éste y otros planos. ${ }^{26}$ Cierto es que en el FA convivían y conviven distintas izquierdas, difíciles de tipificar. ${ }^{27}$ Vale la pena subrayar que un ala de esas izquierdas se atrincheró bajo el argumento de que el tema estaba clausurado por el resultado desfavorable del referéndum del 89 . El argumento se deslizó hacia la percepción de que también existían problemas de oportunidad política en el sentido de que contribuiría a restar votos, en un momento en que "se podía renunciar a todo menos a la victoria". (FERNÁNDEZ HUIDOBRO, 2016) Y esta fue la moción vencedora. Más allá de las mudanzas de propósito que el FA exhibió desde hace más de una década en que gobierna a nivel nacional, el hilo argumental permanece casi invariable pese a las múltiples polémicas. El peso de uno u otro argumento sólo se matizó de acuerdo a la proximidad o lejanía de las coyunturas electorales.

Si se fija la lente en el primer gobierno frentista presidido por Tabaré Vázquez e iniciado en 2005 , se observa que sostenía una marcada adhesión a lo posible. En ese plano se tomaron dos determinaciones: perforar la ley -expresión recurrida para su análisisexplotando las limitadas posibilidades del artículo 4to. ${ }^{28}$ y apelar a la búsqueda de la verdad histórica y a los restos de los desaparecidos. De esta manera, Vázquez declaró exentos de la cobertura de la caducidad los crímenes cometidos fuera del territorio nacional, la desaparición de menores, y la responsabilidad de los mandos y los civiles no cubiertos explícitamente en el texto legislativo. Así fue posible ejercer justicia sobre Bordaberry, el presidente golpista, Blanco, su ministro de Relaciones Exteriores, Álvarez, el jefe militar que había ejercido funciones presidenciales luego del plebiscito denegatorio de reforma constitucional de 1980 y algunos, pocos, responsables de los delitos que resultaban más visibles y que fueron procesados con largas penas. Existieron indudablemente pactos difíciles de conocer, entre ellos que su sentencia se cumpliría en una cárcel especial bajo control militar. En casi todos los casos pendía sobre los perpetradores trámites de extradición pues la justicia argentina se había recuperado del periodo de inacción y gran parte de los delitos se habían cometido en este país vecino al amparo de la Operación Cóndor. Estableció también un convenio con la Universidad de la República para procesar una investigación histórica sobre detenidos desaparecidos en algunos archivos de seguridad e iniciar excavaciones en predios militares. Apeló a una investigación interna dentro de las FFAA que arrojó escasos resultados y que, entre otros infortunios, fue encabezada por algunos perpetradores de antaño. Con tan baja y distorsionada información, el trabajo arqueológico permitió hasta el presente, además de constatar los engaños y deslealtades, la recuperación e identificación de cuatro cuerpos y restos sueltos. El equipo de historiadores

26 Tal como caracterizan algunos especialistas del sistema político partidario uruguayo, el FA se tradicionalizaba, adquiría signos identitarios y espesor histórico. Cf. Dutrénit (1996); Garcé, y Yaffé (2004); Lanzaro (2004).

27Algunos analistas como Ana Laura Di Giorgi (2013, p. 99) valoran que el guiño centrista hacia el electorado "no agota la explicación" de los cambios. Otros señalan que un ala principista dio la batalla en el IV Congreso del FA en el sentido de incorporar al programa la anulación delos artículos de la Ley de Caducidad contrarios a la normativa internacional en materia de derechos humanos. (MOREIRA, 2010). 28 Véase nota 3. 
fructificó en una Investigación histórica de cinco volúmenes, el último de los cuales estuvo consagrado a la búsqueda arqueo-antropológica (URUGUAI, 2007).

Con esas acciones Vázquez se distanciaba notoriamente de sus predecesores. Sin embargo, en su segundo año de gobierno, renació esa clara obsesión de la clase política nacional de poner punto final a la remoción del pasado y proceder a la reconciliación social. Fue entonces que se convocó a la celebración de un Día del Nunca Más. La consigna era: "Nunca más intolerancia y violencia entre uruguayos". Una reacción inmediata de Madres y Familiares replicó poniendo énfasis en que el "nunca más" refería al terrorismo de Estado pero no a una genérica equiparación de la violencia.

La aspiración de laudar los crímenes del pasado con las limitaciones impuestas por el artículo 4to., con la nueva visibilidad que había adquirido el tema a partir de la Investigación histórica y el hallazgo de restos, así como frente a la tendencia de la coalición gobernante de no utilizar las mayorías parlamentarias para deshacerse de la ley, determinaron un nuevo intento. Este segundo momento de democracia directa emprendido principalmente por frenteamplistas de los sectores minoritarios de la coalición, de otros partidos y por algunos independientes, buscó quitar del medio su principal argumento y sustento: la decisión soberana del electorado. Si se trataba del principal obstáculo correspondía entonces que otra nueva decisión soberana, que se tomaría veinte años después, fuera capaz de modificar la anterior. Era por otra parte el único resquicio disponible para cambiar las políticas gubernamentales. Así, desde 2007, la Comisión Nacional por la Nulidad de los Artículos del 1ero. al 4to. de la Ley de Caducidad inició la recolección de las 250 mil firmas necesarias para plebiscitar su anulación. ${ }^{29}$ Y lo hizo en medio de la mayor hostilidad, no sólo de la derecha tradicional sino de las fuerzas mayoritarias del FA. Entre éstas se esgrimió no sólo la argumentación soberanista, sino también la confiabilidad del FA ante la ciudadanía ya que violaría la palabra hipotecada de mantener la Ley. En esta oposición tuvo también un peso indudable el hecho que señaló algún publicista: el "referente principal", es decir, el presidente Vázquez, era contrario a esta propuesta. (VANLENTI, 2008) A la polémica se sumaron también argumentos coyunturalistas, como señalamos antes, relativos a la oportunidad de plebiscitar conjuntamente con las elecciones nacionales. ${ }^{30}$ Sobre la Comisión Nacional por la Nulidad llovieron las acusaciones internas de que su interés no estaba centrado en los muertos, sino en dividir. En particular destacan las expresiones del ex dirigente tupamaro y entonces senador, actualmente Ministro de Defensa Eleuterio Fernández Huidobro. (LABROUSSE, 2009) Asimismo el candidato a la segunda presidencia del FA, igualmente ex dirigente tupamaro, José Mujica, manifestaba poco entusiasmo por la iniciativa y en su habitual tono popular equiparaba la justicia con la venganza. (MUJICA, 2009) También corresponde señalar que Madres y Familiares como organización, puntal en

29 Debe destacarse que ya no era posible derogarla pues había sido aplicada en pocos casos y esa derogación dejaría libre a los procesados y sentenciados.

30 Otros puntos del debate sobre la pertinencia o no de la anulación están anotados en Lessa (2014, p. 109 y ss). 
la campaña de 1989, se abstuvo de participar aunque dejó en libertad a sus integrantes de hacerlo a modo personal. Analizar esta decisión ameritaría un estudio particular sobre el desenvolvimiento de esta y otras organizaciones de la sociedad civil que excede las posibilidades del artículo, aunque no puede soslayarse el peso de la opinión contraria de los referentes y la adscripción política de los integrantes de esta organización.

Los impulsores del plebiscito anulatorio argumentaban que la Ley de Caducidad era incompatible con la legislación internacional suscrita por el Estado uruguayo al margen de que la ciudadanía hubiera decidido mantenerla. ${ }^{31}$ Fundamentaban también su intención de recoger la opinión del recambio generacional y defendían el derecho de estos nuevos ciudadanos para expresarse. Recordaban que, en 2009, la sociedad tenía mucho más conocimiento abierto por la política de verdad. En definitiva, la argumentación en torno al acompasamiento de Uruguay con la legislación internacional fue central, entre otras razones porque desde 2006 la CIDH tramitaba la denuncia contra el Estado uruguayo fincada por Juan y Macarena Gelman, luego de que la justicia nacional archivara el caso de la desaparición forzada de María Claudia García de Gelman y el secuestro de su hija recién nacida, en Uruguay.

Aunque en su V Congreso el FA decidió apoyar la iniciativa a partir "rebelión de las bases" del Partido Socialista y Movimiento de Participación Popular (SEMPOL, 2013), ello no implicó un cambio en la decisión de las direcciones de acompañar el emprendimiento y éste fue un ausente en la campaña electoral de 2009. Por segunda ocasión el intento de apelación a la conciencia de la sociedad uruguaya fracasó. El resultado tuvo una variante: lo hizo por escasísimo número de votos, apenas 46500 , y obtuvo el $48 \%$ del electorado. Recientes estudios sobre el comportamiento de ese electorado muestran que la mayor parte del $48 \%$ estuvo conformado por votantes frenteamplistas de distintos sectores. Constata también la presencia de un voto cruzado de baja intensidad, un $11 \%$, que provino de los partidos tradicionales, independientes, agrupaciones minoritarias de la izquierda y votantes exclusivos por la anulación de la ley. Y concluye que aproximadamente un $13.4 \%$ de electores, que votaron por el FA, no acompañaron su voto con la papeleta de anulación. Este porcentaje implicó que algo más 150000 votantes frenteamplistas no incluyeran la papeleta aprobatoria. Apenas una tercera parte de esa votación habría permitido su anulación. ${ }^{32} \mathrm{Y}$ nos parece importante señalarlo en tanto habilita una mirada hacia la ética política y doctrinal de la izquierda partidaria. Algún tipo de brecha se abrió entre esa izquierda y los movimientos sociales vinculados a la reivindicación de la memoria y la justicia que tendería a profundizarse durante el segundo gobierno frenteamplista.

31 En 1996, bajo el gobierno de Sanguinetti, Uruguay ratificó la Convención Interamericana sobre Desaparición Forzada de Personas. En 2002, durante el gobierno de Batlle lo hizo con el Estatuto de Roma y en 2006, bajo Vázquez, incluyó el delito de desaparición forzada en su legislación interna.

32 La mayoría de los estudios académicos han tendido a mostrar que el voto frenteamplista coincidió con los resultados obtenidos por la anulación de la ley lo que esconde esta realidad incuestionable. Pocos son los que se aplicaron a establecer una visión ajustada sobre esta relación (BURIANO, 2011; RICO, 2014a). 
El "giro a la izquierda" en esta y otras políticas públicas que esperaban con ansia algunos sectores, tampoco se produjo durante el segundo gobierno con la llegada a la presidencia de José Mujica (2010-2015). Revestido del prestigio de su condición de rehén de la dictadura revitalizó con fuerza el discurso de los dos demonios y se sintió habilitado para personalizar el sufrimiento social. Expresó así generosas frases de perdón y disgusto por la prisión que guardaban sus ya "viejitos" victimarios, reflexiones en relación al pasado traumático concebido como una pesada "mochila" que cargaba sobre los hombros del presente. (GALLEGO-DÍAZ, 2011).

Indiscutible es que el segundo gobierno del FA debió enfrentar una presión internacional pues, al fracasar por segunda oportunidad el intento de deshacerse de la Ley, la Comisión Interamericana de Derechos Humanos (CIDH) envío el caso Gelman a la Corte Interamericana de Derechos Humanos (CorteIDH). La sentencia dictada en febrero de 2011, condenó al Estado por su responsabilidad en la desaparición de la madre y el cambio de identidad de la hija, ordenó ubicar a la víctima directa, reparar material y moralmente a las indirectas pero también señaló que: "El Estado debe garantizar que la Ley de Caducidad de la Pretensión Punitiva del Estado... no vuelva a representar un obstáculo..." (CHID, 2011).

No sólo la sentencia introducía una presión sobre la izquierda en el gobierno. A nivel de los familiares y emprendedores existía preocupación pues la justicia uruguaya tenía algunos procesos sin sentencias y las dictadas lo habían sido por delitos del fuero común. De acuerdo a ese criterio, los delitos cometidos en el periodo dictatorial prescribían el 1ero. de noviembre de 2011. Ello motivó un segundo empuje de la justicia. ${ }^{33}$ No existía a esa altura otra posibilidad más que la de un trámite legislativo que hasta entonces se había procurado evitar. Fue así que se formó una comisión de la bancada frenteamplista para obtener un proyecto viable que permitiera a su mayoría parlamentaria deshacerse de la ley. Luego de inenarrables traspiés que supusieron hasta la presencia del Ejecutivo en el Legislativo para impedir la aprobación del proyecto, finalmente se lo sometió al voto. Se aprobó así la ley 18 831 que restableció la pretensión punitiva del Estado, mientras sus artículos 2do. y 3ero. evitaban la prescripción al descontar el plazo del impedido del ejercicio de la justicia por la ley y el momento en que esta fue derogada, al tiempo que caracterizaba los delitos cometidos durante la dictadura como de lesa humanidad.

Como una hidra de mil cabezas la Ley de Caducidad, al decir de Marchesi, volvió "por sus fueros" cuando en febrero de 2013 la SCJ declaró inconstitucionales los artículos relativos al tiempo de prescripción y a la caracterización de los delitos. Una SCJ de composición conservadora, basada en el argumento de la irretroactividad de la ley penal, desconoció además la sentencia de la CorteIDH en el caso Gelman a partir de afirmar que la

33 La SCJ había declarado la inconstitucionalidad de la ley en 2009 para un caso concreto. Ahora lo extendió para unos veinte más y algunos tribunales admitieron la apertura de unas ciento cuarenta causas archivadas. Y existió también una interesante iniciativa ciudadana para promover denuncias porviolaciones de distinto tipo que conjuntó 180 casos que, por cierto, en su mayoría han sido archivados. (ALONSO; RISSO, 2011). 
legislación internacional no había sido aprobada por el Estado en el momento en que se cometieron los crímenes. Ello era una desautorización completa a las normativas internacionales que el Uruguay se había especializado en reconocer tempranamente para demostrar su apego democrático. Retomando a Marchesi (2013, p. 256): "La historia de la ley de caducidad se había terminado. Efectivamente se había cerrado, pero no por las razones esgrimidas por los defensores de la ley 18.831, sino porque los delitos ya estaban prescriptos y no sería necesario mantener un marco legal para defenderlos". Este mismo supremo tribunal, de imagen indefendible, inició casi inmediatamente la remoción de los jueces más comprometidos y formados en el derecho humanitario.

Poco más ha llevado adelante la justicia en Uruguay desde entonces y lo ha hecho con avances y retrocesos a partir de una cierta rebelión de algunos jueces y fiscales pero también ha retrocedido con la complicidad de otros. A ello se suma, como trama que busca entorpecer el develamiento de los delitos de lesa humanidad, el robo de documentación en el laboratorio del Grupo de Investigación en Arqueología Forense asentada en sus medios magnéticos y escritos sin que, hasta el momento, las investigaciones logren aclarar lo ocurrido. Incluso las amenazas directas contra la integridad física de sus académicos muestra el poder que aún mantienen los perpetradores que guardan un inconmovible silencio sobre sus crímenes y la localización de los desaparecidos. Hoy la justicia uruguaya ha logrado dos procesamientos bajo delitos del fuero común, alarga unas pocas causas, concede prisiones domiciliarias a los más connotados responsables de las violaciones de los derechos humanos y sólo en el exterior, en Argentina e Italia, se juzga a algunos perpetradores en el marco de megacausas relacionadas con la Operación Cóndor.

\section{Recapitulando}

Muy a pesar de una Ley cuestionadora del estado, negadora de principios elementales de igualdad heredados de la ya lejana pero siempre presente Revolución Francesa, a 30 años de aquella aprobación, sería impropio no reivindicar las formas de reconocimiento oficial en relación a un pasado violatorio de los derechos humanos que marcaron hitos esenciales. Este reconocimiento estatal se expresó con énfasis en el primer y gran relato plasmado en los 5 tomos de la Investigación Histórica sobre los delitos cometidos y las víctimas que arrojó el régimen dictatorial, producto del gobierno frenteamplista de Tabaré Vázquez (2005-2010). Y, con muchos matices, en el pronunciamiento del presidente Jorge Batlle (2000-2005) sobre la necesidad de investigar, la creación de la COMIPAZ y la declaración del hallazgo, por primera vez en territorio uruguayo, de una "bebé" secuestrada y con cambio de identidad. 
Con ello y luego de 16 años de narrativas oficiales impregnadas del discurso distorsionador y atentatorio contra la tratadística internacional de los derechos humanos, que negaba hechos mientras sostenía la "sana" política de cuentas saldadas a partir de la maniquea idea de una guerra entre dos bandos, el Estado reconoció finalmente que existió culpabilidad y víctimas por su accionar delictivo. Es más se ha evidenciado que la sociedad uruguaya vivió durante casi doce años una cotidianidad de horror. La realidad mostró documentadamente que no se trató de una guerra y que fueron miles y miles los ciudadanos víctimas de un ejercicio violento del poder por el mero hecho de ejercer sus derechos políticos, sindicales y sociales.

Han sido años de escasas pero significativas develaciones sobre la suerte corrida por algunos detenidos desaparecidos. El hallazgo en particular de los restos Julio Castro es emblemático de una patraña discursiva retomada en la transición encabezada por Sanguinetti y avalada por mayorías parlamentarias. Se afirmaba que no había habido asesinatos a sangre fría y que las muertes respondían a "simples excesos" cometidos en la tortura. El hallazgo de los restos del Mtro. Castro demostró su ajusticiamiento por disparo en la cabeza en el lugar de enterramiento y desdijo además que su desaparición se debiera a que abandonó Uruguay. La localización de Macarena Gelman exhibió la complicidad de quienes, como Sanguinetti, afirmaban que en Uruguay el robo de niños no había sucedido, y que ese era un fenómeno privativo de Argentina. Hubo sustracción, traslado de niños a otros países y cambios de identidad.

Las distintas denuncias individuales y colectivas antes los tribunales han alimentado de manera documentada y desgarrante las distintas y brutales violaciones a decenas de miles de hombres, mujeres, entre ellos menores de edad. Hoy en día hay cosas que son impensables de negar socialmente. No obstante, se mantiene ese efecto brutal de un estado democrático que renuncia a la condena penal aunque muy lentamente, en función de los avances en la perforación de la ley, ha podido ligeramente aminorarse y con ello también, muy tenuamente la condena moral. Y hay en esta situación una responsabilidad de comportamientos errantes, zigzagueantes de la izquierda/de las izquierdas que integran el FA en función de sus estrategias en diferentes momentos del transcurrir de los 30 años y, en particular, en los últimos desde que se vislumbró e hizo efectivo el acceso al gobierno nacional.

Algunos de los sucesos mencionados respecto a discusiones, programas, comportamientos electorales, posicionamientos y exabruptos de principales figuras del gobierno frenteamplista orillan a un cuestionamiento sobre los otrora principios éticos esenciales en el campo de los derechos humanos. Se exhibe un FA discorde en su composición y principales figuras respecto a la tradición de la izquierda, a su momento fundacional, a su papel durante la resistencia y como víctima principal de la represión, lo que permite reafirmar que esa aproximación de la izquierda al gobierno y su papel como 
fuerza gobernante, fue modelando su discurso y dirigiéndolo hacia la fractura temporal y temática de su responsabilidad frente a los derechos humanos. Se labró así una interpretación que absolutizaba la victoria como única garantía posible de consagración de los derechos, se fracturó la unicidad y sincronía de los mismos al contraponer los del pasado (cívicos y vinculados con las garantías individuales) a los de un presente por venir (económicos y sociales) sólo garantizados por el ejercicio de gobierno de este partido. Asimismo hizo posible aceptar un discurso hiriente a la izquierda fundante cuyos portadores han sido principales figuras del gobierno frenteamplista.

Este accionar político y discursivo que a veces corre el peligro de hacer coincidir a los artífices de la Ley con los opositores a la misma, en especial desde que el FA es gobierno nacional y de manera más concreta a partir del gobierno de José Mujica (2010-2015) no son ajenas como ha señalado Rico a "conflictos de identidad de la izquierda para asumir su propia historia sesentista” (RICO, 2014b, p. 28). Aún más, evidencian lo que desde avanzada la transición se comenzó a percibir como la tradicionalización del FA, reafirmada luego con componentes novedosos a partir de la incorporación de sectores ajenos a su composición original y con trayectorias encontradas antes de la dictadura e itinerarios ideológicamente interpretativos sobre el pasado reciente muy contrastantes. (DUTRÉNIT, 1996) Luego de once años en el gobierno, esa fuerza política perdió la posibilidad de impulsar una política estatal de verdad, justicia y memoria. Olvidó la esencia de los Principios Joinet en la lucha contra la impunidad, en el sentido de la obligación estatal establecer la verdad, juzgar a los responsables, pero también resguardar la memoria para prevenir las deformaciones históricas, los revisionismos y negacionismos bajo el entendido de que la historia de la opresión de un pueblo forma parte de un patrimonio que debe ser preservado y mantenido en la memoria social. (ORGANIZACIÓN DE LAS NACIONES UNIDAS, 2007).

Es esta memoria la que ocupa el primer plano a la hora de la conmemoración de la tragedia que significó la conculcación del derecho de las víctimas por la vía legislativa y por la voluntad soberana. ¿Cómo se conmemoran los actos fundantes de un oprobio nacional cuando hay una voluntad estatal de imponer el olvido social? Y cuando esta voluntad confluye con tendencias del imaginario de alto arraigo y una práctica societal que sistemáticamente expresa "[...] temor al conflicto, a la confrontación[...]" y niega "[...] todo aquello sobre lo que no haya consenso". ${ }^{34}$ Especialmente cuando ese consenso pretende presentarse, al modo de los teóricos de la impunidad, como "la etapa superior del olvido" Moulián (apud LECHNER; GÜELL, 1998).

Una visión posible y en absoluto carente de sustento es la de un réquiem final para la sociedad uruguaya, esa que por irreflexión, al decir de Rico "banalizó el mal", se alejó de la moral, legitimó la Ley con su voluntad soberana y consagró la cultura de la impunidad.

34 Esta valoración de Rafael Sanseviero es de su texto, Condena, tolerancia y negación: el aborto en el Uruguay. Centro internacional e información para la Paz, Montevideo, 2003,p. 238 y 205. Nosotros la tomamos de la referencia que de ella hace Rico (2014a, p. 20). 
(RICO, 2014b, p. 25, 29, 31) A salvo queda que no está en la propuesta del autor citado este fijismo histórico, sino la intención de una fotografía actual de la democracia realmente existente y del estado de la sociedad uruguaya.

Generalmente se conmemora para encontrar en el espesor del pasado la esencia de nuestro ser actual. La conmemoración es también posible para repudiar aquello que no queremos ser, a lo que no queremos pertenecer ${ }^{35}$ En este plano debería inscribirse la conmemoración actual. En un recurrir al debate que la sociedad uruguaya se debe, en una apelación a la esencial capacidad subversiva de la memoria aquella, que al decir de Todorov, (TODOROV, 2016) los totalitarismos deploran en tanto cuestiona los relatos hegemónicos labrados por el poder, por su potencial resignificante de aquello que fue incluido en el imaginario social, por su capacidad de revivir el conflicto y cuestionar "lo que somos como sociedad". Claro que, como bien señala Isabel Pipper, (PIPPER SHAFIR, 2013) la memoria no es un ente con capacidad transformadora en sí mismo. Esta capacidad/responsabilidad está situada en los sujetos sociales. Y a ellos les pertenece el peso de esta conmemoración.

\section{Referências (aqui é subtítulo, em baixo é "corpo do texto" sem recuo)}

ACHARD, Diego. La transición en Uruguay. Montevideo: Instituto Wilson Ferreira Aldunate, 1992.

ALLIER, Eugenia. Batallas por la memoria: los usos políticos del pasado reciente en Uruguay. Montevideo: Trilce-IIS/UNAM, 2010.

ALONSO, Jimena; RISSO, Mariana. Una acción contra el silencio. Nuevas formas de denuncia de delitos de lesa humanidad en Uruguay. Una reflexión a partir de octubre de 2011. Contenciosa, Santa Fe, n. 5, 2015. Disponible en: <http://www.contenciosa.org/ Sitio/VerArticulo.aspx?i=51>. Acceso en: 15 mayo 2016.

ARGENTINA. Ley 23.492. Punto Final promulgada el 24 de diciembre de 1986. Disponible en: $<$ http://www.desaparecidos.org/nuncamas/web/document/ nacional/ley23492.htm>. Acceso en: 10 abr. 2016.

35 En 1996 Alemania fijó el 27 de enero como el día del Holocausto y lo conmemoró con una serie de prohibiciones a portales nazis y varias instancias de reflexión. 
ARGENTINA. Ley 23.521. Obediencia Debida, decretada el 8 de junio de 1987. Disponible en: $<$ http://www.desaparecidos.org/nuncamas/web/document/ nacional/ley23521.htm>. Acceso en: $10 \mathrm{abr} .2016$.

BUCHELI, Gabriel et al. Vivos los llevaron: historia de la lucha de Madres y Familiares detenidos desaparecidos. Montevideo: Trilce, 2005.

BURIANO, Ana. Derechos, trauma social y restitución. Sincronía y unicidad: el caso uruguayo. Andamios, México, n. 18, p. 89-116, 2012.

BURIANO, Ana. El golpe de Estado uruguayo del 27 de junio de 1973 en las voces de los políticos tradicionales. Historia, Voces y Memoria, Buenos Aires, n. 5, p. 129-156, 2013.

BURIANO, Ana. Ley de caducidad en Uruguay y esencia ético-política de la izquierda. Perfiles Latinoamericanos, México, n. 38, p.173-203, 2011.

CAÑAS, Gabriela. Entrevista a Macarena Gelman: "fui un regalo robado". El País Semanal, Madrid, 10 de agosto de 2008. Disponible en: <http://www.elpais.com/ articulo/portada/Fui/regalo/robado/elpepusoceps/20080810elpepspor_4/Tes>. Acceso en: 16 jun. 2016.

CENTRO URUGUAY INDEPENDIENTE. Documentos referendum. Montevideo: CUI, 1987. (Documento político, n. 2).

CHID. Caso Gelman vs. Uruguay. Sentencia del 24 de febrero de 2011 (Fondo y Reparaciones). Disponible en: <http://fueromilitar.scjn.gob.mx/Resoluciones/ seriec_221_esp1.pdf >. Acceso en: 15 abr. 2016.

COLLINS, Cath. Post-transitional justice: human rights trials in Chile and El Salvador. Pennsylvania: Penn State University Press, 2010.

DE GIORGI, Álvaro. Las defensas blanca y colorada de la ley: entre el mal menor y el broche de oro' de la 'restauración modelo'. En: MARCHESI, Aldo (Coord.). Ley de Caducidad un tema inconcluso: momentos, actores y argumentos. Montevideo: Trilce/CSIC, 2013. p. 17-60.

DE GIORGI, Ana Laura. El frente amplio y su laberinto. La izquierda uruguaya frente a la ley de caducidad. En: MARCHESI, Aldo (Coord.). Ley de caducidad un tema inconcluso: momentos, actores y argumentos. Montevideo: Trilce/CSIC, 2013. p. 61-102.

DE GREIFF, P. Algunas reflexiones acerca del desarrollo de la justicia transicional. Anuario de Derechos Humanos, Chile, n. 7, p. 17-39, 2011. 
DEMASI, Carlos. Un repaso a la teoría de los dos demonios. En: MARCHESI, Aldo et al. (Coord.). El presente de la dictadura: estudios y reflexiones a 30 años del golpe de Estado en Uruguay. Montevideo: Trilce, 2003. p. 67-74.

DUTRÉNIT, Silvia. El frente amplio y la reproducción de la identidad política. Nueva Sociedad, Caracas, v. 144, p. 126-137, 1996.

DUTRÉNIT, Silvia. Los abriles uruguayos y el informe final de la comisión para la Paz. Observatorio Político: Informe de Coyuntura. Montevideo, n. 4, p. 130-134, 2003.

DUTRÉNIT, Silvia; VARELA, Gonzalo. Tramitando el passado: violaciones de los derechos humanos y agendas gubernamentales en casos latinoamericanos. México: FLACSO, 2010.

ESPINOZA CUEVAS, Víctor; ORTIZ, María Luisa; ROJAS BAENA, Paz. Comisiones de la verdad ¿un camino incierto?: estudio comparativo de las comisiones de verdad en Argentina, Chile, El Salvador, Guatemala y Sudáfrica desde las víctimas y las organizaciones de derechos humanos. 2002. Disponible en: <http://www.apt.ch/ pub/library/Estudio2.pdf $>$. Acceso en: 27 jun. 2016.

FERNÁNDEZ HUIDOBRO, Eleuterio. A los iguales, Montevideo: Mirando al Sur, 2005. Disponible en:<http://mirandoalsur.blogia.com/2005/021201--hr-h2-u-a-los-iguales-h2-u.php>. Acceso en: 25 abril 2016.

FERREIRA, Juan Raúl. El 20 de mayo del 76. Uypress, Montevideo, 13 de mayo 2016. Disponible en:<http://www.uypress.net/index_1.html>. Acceso en: 10 abr. 2016.

GALLEGO-DÍAZ, Soledad. "Yo no miro atrás, pero no puedo imponer a los ciudadanos mi manera de ser". Entrevista a José Mujica, presidente de Uruguay. El País, Madrid, 17 abr. 2011. Disponible en: <www.elpais.com/articulo/reportajes/miro/ puedo/imponer/ciudadanos/manera/ser/elpepusocdmg/20110417elpdmgrep_4/Tes>. Acceso en: 17 abr. 2011.

GARCÉ, Adolfo; YAFFÉ, Jaime. La era progresista. Montevideo: Fin de Siglo Editorial, 2004.

GILLESPIE, Charles. Negotiating democracy: politicians and generals in Uruguay. EUA: Cambridge University Press, 1991.

HAYNER, Priscilla. Unspeakable truths: confronting state and atrocity. New York: Routledge, 2001.

JELIN, Elizabeth. Los trabajos de la memoria. España: Siglo XXI de España, 2002.

LABROUSSE, Alain. Una historia de los tupamaros: de Sendic a Mujica. Montevideo: Fin de Siglo Editorial, 2009. 
LANZARO, Jorge. La izquierda se acerca a los uruguayos y los uruguayos se acercan a la izquierda: claves de desarrollo del FA. En: LANZARO, Jorge (Coord.). La izquierda uruguaya: entre la oposición y el gobierno. Montevideo: Fin de Siglo Editorial, 2004. p. 13-108.

LECHNER, N.; GÜELL, P. Construcción social de las memorias en la transición chilena. Social Science Research Council: Memorias Colectivas de la Represión en el Cono Sur. Montevideo, n. 15-16, p. 5, nov. $1998 . \quad$ Disponible en: $<$ https://diplomadoeducacionmemoriayddhh.files.wordpress.com/2014/05/lechner-yguell.pdf>. Acceso en: 26 abr. 2016.

LESSA, Francesca. ¿Justicia o impunidad?: cuentas pendientes en el Uruguay post-dictadura. Montevideo: Debate, 2014.

MARCHESI, Aldo. Conclusión: la sinuosa permanencia de la caducidad. En: MARCHESI, Aldo (Coord.). Ley de Caducidad un tema inconcluso: momentos, actores y argumentos. Montevideo: Trilce/CSIC, 2013. p. 247-256.

MARKARIAN, Vania. De la lógica revolucionaria a las razones humanitarias: la izquierda uruguaya en el exilio y las redes transnacionales de derechos humanos (1972-1976). Cuadernos del Claeh, Montevideo, n. 89, p. 85-108, 2004.

MOREIRA, Constanza. Ley de caducidad: el legado de Hugo Cores. Montevideo: La República, 2010. Disponible en:<http://www.larepublica.com.uy/contratapa/428973-ley-de-caducidadel-legado-de-hugo-cores>. Acceso en: 25 oct. 2010.

MUJICA, José. No sé qué ideología tienen los Kirchner. Buenos Aires: La Nación, 2009. Disponible en:<http://www.lanacion.com.ar/1173730-no-se-que-ideologia-tienen-loskirchner>. Acceso en: 15 abril 2016.

ORGANIZACIÓN DE LAS NACIONES UNIDAS. Consejo Económico Y Social. Las directrices de Joinet revisadas. La administración de la justicia y los derechos humanos de los detenidos. Informe final revisado acerca de la cuestión de la impunidad de los autores de violaciones de los derechos humanos (derechos civiles y políticos) preparado por el Sr. L. Joinet de conformidad con la resolución 1996/119 de la Subcomisión. En: COMISIÓN COLOMBIANA DE JURISTAS. Principios internacionales sobre impunidad y reparaciones: compilación de documentos de la Organización de las Naciones Unidas. Bogotá: Comisión Colombiana de Juristas, 2007.

PIPPER SHAFIR, Isabel. Introducción: la conmemoración como búsqueda de sentido. Revista Pleyade, n. 11, 2013. Disponible en: <http://www.academia.edu/22210902/ Introducci\%C3\%B3n_La_conmemoraci\%C3\%B3n_como_b\%C3\%BAsqueda_de sentido $>$. Acceso en: 27 jun. 2016. 
PUCHET, Martín. Elecciones, cambios políticos y nuevos gobiernos en Uruguay. Secuencia. Revista de Historia y Ciencias Sociales, México, n. 18, p. 203-227, sept./dic. 1990.

REY TRISTÁN, Eduardo. La izquierda revolucionaria uruguaya, 1955-1973. Sevilla: CSIC; Escuela de Estudios Hispano-Americanos; Universidad de Sevilla/Diputación de Sevilla, 2005.

RICO, Álvaro. Cómo nos domina la clase gobernante: orden político y obediencia social en la democracia posdictadura. Uruguay 1985-2005. Montevideo: Trilce, 2005.

RICO, Álvaro. Cómo votaron los partidos en el plebiscito contra la caducidad en 2009 y la historia contra la impunidad, 2006-2013. Montevideo: Trilce; Facultad de Humanidad y Ciencias de la Educación-UdelaR, 2014a.

RICO, Álvaro. La suspensión del juicio: a modo de introducción. En: RICO, Álvaro (Coord.). Cómo votaron los partidos en el plebiscito contra la caducidad en 2009 y la historia contra la impunidad, 2006-2013. Montevideo: Trilce/Facultad de Humanidad y Ciencias de la Educación-UdelaR, 2014b. p. 15-31.

RICOEUR, Paul. La memoria, la historia y el olvido. Argentina: FCE, 2004.

RINCÓN, Tatiana. Verdad, justicia y reparación: la justicia de la justicia transicional. Bogotá: Universidad del Rosario, 2010.

SANGUINETTI, Julio María. El temor y la impaciencia: ensayo sobre la transición democrática en América Latina. Buenos Aires: FCE, 1991.

SEMPOL, Diego. A la sombra de una impunidad permanente. El movimiento de Derechos Humanos y la ley de Caducidad. En: MARCHESI, Aldo (Coord.). Ley de caducidad un tema inconcluso: momentos, actores y argumentos. Montevideo: Trilce/CSIC, 2013. p. 103-138.

SKAAR, Ellin. “Puede la independencia judicial explicar la justicia postransicional?. América Latina Hoy, Salamanca, v. 61, p. 15-49, 2012.

TEITEL, R. Genealogía de la justicia transicional. En: REÁTEGUI, F. (Ed.). Justicia transicional: manual para América Latina. Brasilia: Comisión de Amnistía del Ministerio de Justicia de Brasil; Nueva York: Centro Internacional para la Justicia Transicional, 2011. p. 135-172.

TODOROV, Tzvetan. Los dilemas de la memoria. Cátedra latinoamericana Julio Cortázar. Conferencia magistral. Disponible en: <http://www.jcortazar.udg.mx/ sites/default/files/TODOROV.pdf>. Acceso en: 2 jun. 2016.

URUGUAY. Ley $n^{\circ} 15.848$. Funcionarios militares y policiales. Montevideo: Poder Legislativo, 1986. 


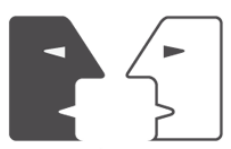

ANTIITESES

URUGUAY. Ley $n^{\circ}$ 18. 831. Pretensión punitiva del Estado. Montevideo: Poder Legislativo, 2011.

URUGUAI. Presidencia de la República. Investigación histórica sobre detenidos desaparecidos: en cumplimiento del artículo 4 de la Ley 15.848. Montevideo: IMPO, 2007.

VALENTI, Esteban. Yo no firmo ni voto. Montevideo: Bitácora, 2008. Disponible en: <http://www.bitácora.com.uy/noticias_1468_html>. Acceso en: 30 mayo 2016.

VARELA, Gonzalo. Uruguay: de l'état libéral á la république militaire. 1981. Tesis (Doctorado en Ciencias Sociales) - París: École des Hautes Études, 1981.

Recebido em 04/07/2016

Aprovado em 24/03/2017 